\title{
Analysis of Improving Economic Benefits of Higher Education
}

\author{
Lv Shikuo \\ Tianjin University of Finance and Economics, tjufe \\ Tianjin, China
}

\begin{abstract}
Improving the economic benefits of higher education can effectively promote social development and accelerate the transformation to a strong science and technology country. In order to measure the economic benefits of higher education, in addition to short-term material output, indirect benefits of talents in different social fields need to be considered. Therefore, in order to improve the economic benefits of higher education, it is necessary to effectively improve the allocation of university resources. Starting from education economics, this paper addresses the main factors hindering the improvement of economic benefits of higher education, such as unbalanced education development, unprofessional financial management, unreasonable professional setting and irrational student enrollment expansion, so as to enable colleges and universities to accurately send talents to the society and create high-quality and high-efficiency economic benefits.
\end{abstract}

Keywords-Higher education; Economic benefit; Financial; Management

\section{INTRODUCTION}

With the development of society, the importance of talents for the development of a country and a nation has become more and more prominent, and so has education. President $\mathrm{Xi}$ Jinping proposed that education determines the present of mankind, so as to the future. Improving the economic benefits of higher education cannot be ignored in improving national economic level and social future development. To ensure the priority development of education, education funding must be constantly increased, in 2017, the total investment of education in China was 4255.7 billion yuan, an increase of $9.43 \%$ over the previous year. The state financial expenditure of education was 3420.4 billion yuan, an increase of 8.94 percent over the previous year. High investment of higher education will certainly bring high expected economic benefits. As the carrier of education, colleges and universities keep sending talents to the society to create economic benefits. However, there is still a disconnect between universities and social enterprises, and there are still some deficiencies in the allocation and use of investment funds. To improve the economic benefit of higher education, we need to face various factors of influence and limitation.

\section{THE CONTENT AND SIGNIFICANCE OF ECONOMIC BENEFIT OF HIGHER EDUCATION}

Higher education aims to cultivate talents with high professional skills, so as to promote the improvement and development of science and technology to meet the needs of promoting social progress. Economic benefit usually refers to the relationship between input and output. The output of higher education is indirect, so the economic benefit of higher education is the relationship between the indirect output of higher education and the input cost of higher education. To measure the economic benefits of higher education, we should not only consider the material benefits of higher education's investment in the short term, but also make clear the indirect output from the knowledge and capacity reserve of talents in different construction areas of the national society brought by higher education to the national economy. There are two ways to improve the economic benefits of higher education, on the one hand, to make use of reasonable and effective education resources investment can produce contributions to the construction of the talents for the society, making social progress in all aspects of multi-level, and further improve the national income, on the other hand, reduce the cost of training talents, under the fixed capital investment, increase educational investment, realize the optimization of the education cost.

\section{FACTORS INFLUENCING THE ECONOMIC BENEFITS OF HIGHER EDUCATION}

\section{A. Unbalanced education development.}

In China, University of 985 Project and University of 211 Project are regarded as synonyms for high-quality higher education, and their regional distribution is highly unbalanced. According to statistics, among 39 "project 985" universities and 112 "project 211" universities, there are 26 "985" universities in the eastern region, and 71 "211" universities, accounting for $66.7 \%$ and $63.4 \%$ respectively. There are 6 "985" and 17 "211" universities in the central region, accounting for $15.4 \%$ and $15.2 \%$ respectively. The "985" and "211" universities in the western region are 7 and 24 respectively, accounting for $17.9 \%$ and 21.4 percent of the total. High-quality colleges and universities in the eastern region are dense and sparse in the central and western regions. Among the 42 "double-first-class" universities, the original 39 "project 985" universities were all selected, and only add 3 more middle and western universities including Zhengzhou University, Yunnan University and Xinjiang University. It can be seen that the new round of high quality education construction adjustment has not changed the unbalanced and 
insufficient regional distribution pattern. In addition, higher education requires individuality and character. However, in China, the boundary between institutions of higher learning is not clear, the division of labor is not clear, the orientation of running schools is not correct. Higher educational institutions tend to be more and more similar. These problems have some adverse effects on the balanced and coordinated development of higher education ecosystem.

\section{B. Unprofessional financial management}

If the university is regarded as an enterprise, education will be the core product of it, and providing talents for the society through education service is the ultimate goal it should achieve. The financial management of colleges and universities directly affects the allocation of funds in production activities and plays a vital role in the production goals. The implementation of the strategy of rejuvenating the country through science and education has given priority to the development of education. As a result, the financial system of education in higher education has made great progress and development, providing a guarantee for universities to provide high-quality education services. How to strengthen financial management to improve the utilization efficiency of resources and cultivate more social applicable talents has become an important issue that colleges and universities need to solve. At present, financial management in colleges and universities lacks systematic evaluation indicators, which makes the reasonable allocation of property resources in colleges and universities lack standards. While emphasizing teaching and scientific research as the center, colleges and universities ignore the role of financial management in the construction and development of them, which is often managed by non-professional personnel in the leading position of financial management. The lack of financial management standards and professionalism has greatly restricted the improvement of economic benefits of higher education.

\section{Unreasonable professional setting}

Whether college graduates are of high value to society is closely related to the professional setting of colleges and universities. Now, colleges and universities are still expanding education scale and pursuing the universality of professional setting, which makes colleges and universities ignore the market economic significance of individual majors and set up some majors with little or no social demand. The homogenization of majors causes an increase in the number of graduates with the same major, which leads to an increase in the employment pressure of college graduates. In order to solve the employment problem, colleges and universities continue to increase their investment and energy, and this will waste the resources. In addition, the current society is in the rapid development stage of great changes. The market of economic and social human resources needs schools to cultivate talents in line with social development. However, the professional setting of colleges and universities is lagging behind the real world, as a result, graduates' knowledge and skills are out of touch with social needs.

\section{Irrational student enrollment expansion}

In recent years, in order to popularize higher education, almost all universities have expanded enrollment. The growing number of students makes the number of college students higher than that colleges can accommodate. First, it increases the management difficulty. The addition and loss of teaching equipment reduced the investment of education funds. Second, it has increased the teaching pressure of teachers and limited the improvement of teaching level. The quality of school running cannot be improved reasonably. Since 2014, the number of college graduates has exceeded 7 million, reaching 7.27 million. The number has been climbing for years, reaching 8.2 million by 2018. The difficult management of students and the high pressure of employment have hindered the improvement of the economic benefits of higher education.

\section{IMPROVING THE ECONOMIC BENEFITS OF HIGHER EDUCATION}

It is very important to adjust the regional distribution imbalance of high quality education for the long-term development of China's higher education. On the one hand, having more high-quality education resources will promote the economic and social development of the region. Therefore, in order to change the regional distribution of high-quality higher education resources, the first step is to increase regional economic construction and improve regional economic level. On the other hand, when carrying out the macro layout of higher education, the state should give due consideration to the appropriate preference to the central and western regions where high-quality education resources are insufficient without reducing the financial investment of high-quality higher education resources in the east. In addition, the local government also should play a proper role, join the national support for the construction of high-quality higher education, encourage and support to attract and cultivate high quality teachers in colleges and universities.

The quality of financial management in colleges and universities is closely related to the attention and understanding degree of principals to financial management. Therefore, strengthening the financial management consciousness of university leaders is a key factor to solve the financial management problem. The state and provincial financial departments should formulate financial evaluation indicators, provide guidelines and standards for financial management and provide direction for financial system of colleges and universities. At the same time, it is necessary to strengthen the financial accounting knowledge training for college principals so that they can master the basic knowledge of financial accounting. Cultivating the financial professionalism of university principals to make sure that the financial control of colleges and universities is reasonable. Improving job responsibilities and implementing dynamic management to restrain financial behavior. Appropriate management measures shall be formulated for financial revenues and expenditures. Professional financial allocation of colleges and universities is the most direct way to improve the economic benefits of higher education. 
The professional setting of colleges and universities involves the allocation and integration of talents, society and resources. The development of science and technology, economy and society has put forward new requirements for high-level talents. The importance of interdisciplinary science is increasing in technological innovation. Schools should participate in social research when setting up their majors, so that they can effectively understand social needs and allocate their majors in practice, which can effectively improve their own economic benefits. At the same time, colleges and universities should introduce social resources into education, and social resources can provide universities with human resources needs to keep pace with The Times. The integration of universities and society can enable higher education to cultivate talents in line with social needs, so that the skills possessed by graduates can be fully used in social production activities, increase the output of higher education, and improve the economic benefits of higher education.

The service of higher education has its particularity. Under certain education resources, the continuous expansion of the number of students will lead to the increase of education pressure and the decrease of education quality. First of all, colleges and universities should constantly adjust the allocation of teaching resources, strengthen the faculty. Colleges and universities should absorb the resources of excellent teachers, meanwhile, they should carry out academic exchanges to provide more further study opportunities for the in-service teachers to ensure the sufficient vitality of teaching. Secondly, the university should strengthen its employment guidance, conduct in-depth cooperation with the society and enterprises, accurately transport talents for the society, and avoid the separation between education and the reality. Only by applying knowledge to improve the competitiveness of graduates can they improve their competitiveness.

\section{CONCLUSION}

Above all, in order to effectively improve the economic benefits of higher education, it is necessary to find the pain point that hinders its promotion. Starting from education economics, this paper has solved the problems of unbalanced education development, unprofessional financial management, unreasonable professional setting and irrational student enrollment expansion. By integrating education resources and effectively utilizing education investment, collages and universities can improve the economic benefits of higher education.

\section{REFERENCES}

[1] Ran Jin, "Analyses on economic benefits of higher education in China," Education Teaching Forum, 2013: XXXVIII.

[2] Shi Jinghuan, "Constructing the Modern University System Needs the Root, the Soul and the Bone", 2014: IV.

[3] Wang Shanmai, "Bussiness School/Capital Institute for Economics of Education, Beijing Normal University" China Economics of Education Review, 2017: VI.

[4] Tang Tao, "Analysis on characteristics and influencing factors of economic benefit of higher education," [J] China International Business, 2018: IX.

[5] Zhang Ying, "Discussion on the Features of Economic Benefit in Higher Education and Influencing Factors," Value Engineering, 2010: XXI.

[6] Huang Tao, "Discussion on Internal Control of Financial Management in University," Journal of Central University of Finance \& Economics, 2015:S2. 